\title{
Characterisation of Electric Vehicle Fast Charging Forecourt Demand
}

\author{
James Dixon, Keith Bell, Ian Elders \\ Dept. of Electronic and Electrical Engineering \\ University of Strathclyde, Glasgow, United Kingdom \\ \{james.dixon, keith.bell, i.elders $\} @$ strath.ac.uk
}

\begin{abstract}
Not all Electric Vehicle (EV) charging in future will take place at drivers' homes or on-street; at least some will take place at fast-charging stations which are likely to be analogous to today's petrol station forecourts. This paper presents a Monte Carlo (MC)-based method for the characterisation of the likely demand profile of $\mathrm{EV}$ fast charging forecourts based on activity profiles of existing petrol stations, derived from smartphone users' anonymised positional data captured in the 'Popular Times' feature in Google Maps. Unlike most academic works on the subject to date which rely on vehicle users' responses to surveys, these data represents individuals' actual movement patterns rather than how they might recall or divulge them. Other inputs to the model are generated from probability distributions derived from EV statistics in the UK and existing academic work. A queueing model is developed to simulate busy periods at charging forecourts. The output from the model is a set of expected time series of electrical demand for an EV forecourt and statistical analysis of the variation in results. Finally, a method is presented for the probabilistic evaluation of the combined loading of an EV forecourt and existing demand; this could be used to assess the sufficiency of existing network capacity and the potential for 'smart' technologies to facilitate increasing penetration of EVs.
\end{abstract}

\section{Index Terms - Electric Vehicles, Fast Charging, Monte Carlo}

\section{INTRODUCTION}

\section{A. Background}

There are around 31 million cars registered on the road in Great Britain [1]. The UK Government has pledged to outlaw the sale of purely petrol or diesel-powered cars by 2040 [2]. Therefore, a number approaching that scale of vehicles could be electric (either pure battery-powered vehicles or plug-in hybrids) within the next two to three decades. Compared to the current GB stock of around 125,000 electric vehicles [3], this is a monumental increase. While it is often assumed in the large amount of academic work on the subject that Electric Vehicles (EVs) will be charged overnight at home slowly at rates of 3-7 $\mathrm{kW}$, there are factors that bring this assumption into question:

1) Lack of off-street parking: in a UK Department for Transport survey of 1,100 'representative adults', only $57 \%$ had access to off-street parking. It is assumed that the remaining 43\% would have nowhere to install an EV charge point [4].

2) Range anxiety: as the range of electric vehicles is, to date, typically shorter than their fossil-fuelled counterparts, there is demand for rapid on-route charging facilities to enable long journeys or subsequent journeys with not enough time between them for sufficient slow charging.

3) Changing car ownership: the UK Government's innovation agency Innovate UK believes that more than $90 \%$ of EVs are 'sold' under Personal Contract Plans [5]. Along with recent growth in car clubs [6], personal cars are effectively being rented; this is pushing the market towards a mobility-asa-service environment. This could have an influence on charging behaviour; if the EV is not owned outright, users may be more likely to opt for fast charging to enhance convenience at a potential detriment to battery longevity [7].

These factors are contributing to the ongoing growth in EV fast charging infrastructure [8]. It is envisaged by National Grid, the GB Transmission System Operator, that dedicated EV 'forecourts' with chargers rated in the hundreds of kilowatts that are able to fully recharge vehicles in a handful of minutes could be commonplace in the near future [9].

'Fit and forget' approaches to network reinforcement in the face of significant demand growth, such as that presented by a rapid growth in EV fast charging infrastructure, could lead to overinvestment in, and underutilization of, the network [10]. Instead, innovative smart grid technologies can be used to build active networks that exploit the inherent diversity and flexibility in electricity use; the aim being to spread energy use more evenly across the day, increasing network utilization and reducing the cost of energy delivered [11]. New planning tools based on probabilistic analysis of the temporal and spatial variation of demand are required in order for the potential benefits of these approaches to be evaluated.

\section{B. Objective}

The objective of this work is to develop a probabilistic method for the characterisation of EV fast charging forecourts based on the activity of current UK petrol stations derived from smartphone users' anonymised positional data. Statistical comparison of the simulated EV forecourt demand to that of an existing distribution network is presented as an example of a method that could inform future network investment planning in high EV-uptake scenarios, including evaluation of smart grid technologies in enabling an economically efficient transition to an energy system that can support electrified transport.

This work was carried out as part of the Engineering and Physical Sciences Research Council (EPSRC) Centre for Doctoral Training in Future Power Networks and Smart Grids at the University of Strathclyde; the authors also acknowledge the assistance of SP Energy Networks. 


\section{Literature Review}

Huang and Infield [12], Beltramo et al. [13] and Lojowska et al. [14] each present models for study of the impact of domestic EV charging on distribution networks based on probabilistic approaches. All three studies are based on the use of transport survey data as the input to the model, which introduces unreliability inherent in self-reported surveys.

Etezadi-Amoli et al. [15] present a case study on the impact of rapid-charge EV stations on a US distribution network, assuming that the stations' peak demand occur coincidentally with the current network peak. This may be unduly pessimistic; a more thorough analysis would consider the temporal variation in network and charging demand.

Bae and Kwasinski [16] present a method for predicting the demand profile of a rapid EV charging station based on a multiple server, single queue (M/M/s) Queue Theory model with a Poisson-Arrival-Location Model (PALM) to simulate traffic flow. The paper presents an interesting model from the underlying assumption that EV fast-charging activity at any given time is primarily driven by traffic flow. It is suggested that in reality, the activity of such a forecourt is likely to be dependent on many other factors as well, such as the time of day, the local employment patterns and proximity to other key infrastructure and points of interest.

In this paper, the fast-charging behaviour of EV users is assumed to be the same as the fuelling behaviour of combustion engine vehicle users, hence the usage patterns of $\mathrm{EV}$ forecourts are assumed to be the same as existing petrol stations.

\section{Petrol Station Activity Data-Google Maps Popular Times}

In their Popular Times feature (visible on the Google Maps website or smartphone application), Google collects and stores anonymised positional data from their smartphone users to allow other users to see when a certain venue is likely to be busy or not. The data provides an average popularity for each day of the week, as a percentage value of the weekly peak popularity. An example is shown in Fig. 1.

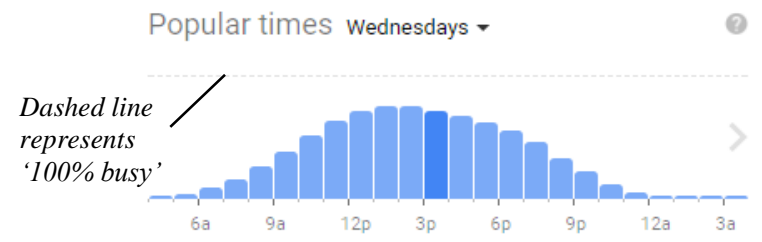

Figure 1. Example of Google Maps Popular Times curve for Wednesdays at Tesco Petrol Station, Glasgow G21 1YL [17]

Popular Times data was retrieved for a sample of 2,256 existing petrol stations in Great Britain in areas surrounding major cities (Scottish Central Belt, Glamorgan, Yorkshire, Greater London, Greater Manchester, West Midlands, Avon, Merseyside and Tyneside). Of the 2,256, 476 are supermarketowned, 1,694 are independent/oil company-owned and 86 are at motorway service stations. For comparison, there were 8,476 petrol stations in the UK at the end of 2016 [18]: the sample used in this work makes up just over a quarter of the population.

\section{E. Limitations to the Data}

Firstly, the Google data is only captured from smartphone users who have the Google Maps application installed and have location history turned on (though this is the app's default setting). While this method is likely to capture a great many users $(81 \%$ of UK adults -37 million people - were smartphone users in 2016 [19] and Google Maps was installed on 57\% of US smartphones in 2017 [20]), this could introduce a selection bias in the results if those who are less likely to be captured in the data are more likely to visit petrol stations at certain times.

Secondly, the petrol station popularity data is presented as an averaged percentage of the peak. This means that there is no indication of an absolute number of users; this paper assumes that the peak equates to all pumps being used in a petrol station and every charging station being used in an EV forecourt. Also, no seasonal variation can be derived from the data.

Despite these two limitations, it is suggested that using smartphone locational data for petrol station activity holds distinct advantages over survey-based data or traffic flow data.

\section{METHOD}

\section{A. Overview}

The MC-based method to characterise the demand profile of an EV forecourt is split into two parts:

i. A state sampling simulation to derive the number of vehicle arrivals per hour for an $\mathrm{EV}$ forecourt on a given day, based on the assumption that their activity will be the same as those of existing petrol stations.

ii. A time sequential simulation to characterise the power demand of the forecourt in allowing users to charge their EVs, given the arrival profile in (i), according to a set of parameters probabilistically assigned to each vehicle and a queueing model developed to simulate busy periods at the forecourt.

\section{B. State Sampling Simulation}

Using Google Maps Popular Times data (such as that in Fig. 1) for all petrol stations in the sample for a selected day of the week, a Cumulative Distribution Function (CDF) such as that shown in Fig. 2 is formed for each hour of the selected day.

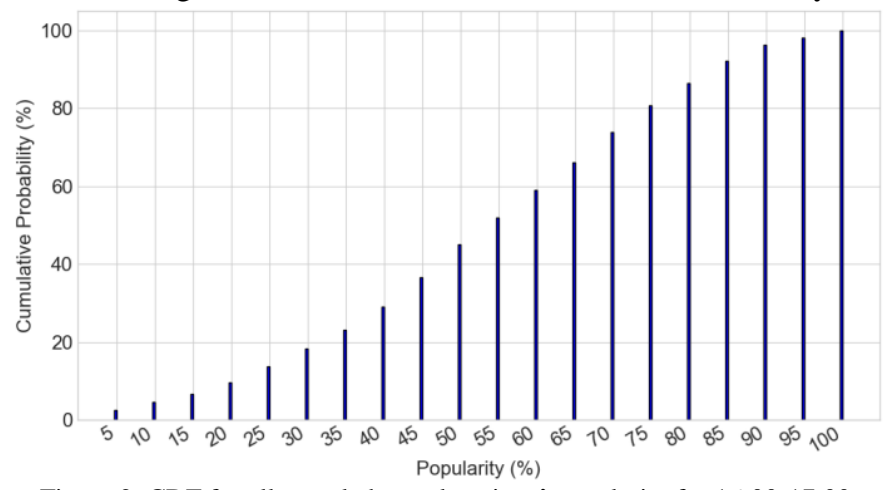

Figure 2. CDF for all sampled petrol stations' popularity for 16:00-17:00, from Saturday popularity data 
For each MC trial, these CDFs were sampled from to derive a popularity profile (\%) for the simulated EV forecourt (Fig. 3).

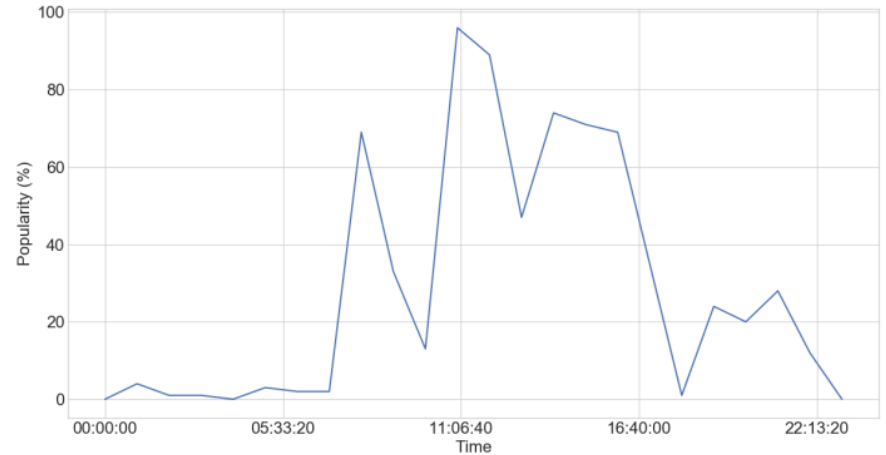

Figure 3. Popularity profile for one $\mathrm{MC}$ trial based on petrol station popularity data for Saturday

The average number of pumps at a UK petrol station was 7.3 in 2013, according to [18]. This is used to derive the average number of cars at a petrol station at each of the hourly time slices, by multiplying the popularity (\%) by 7.3 and rounding to the nearest whole number.

Little's theorem (1) can be used to derive the average arrival rate $\bar{\lambda}$ for a given hour of petrol station activity, given an average number of agents in the system $N$ (i.e. the forecourt occupancy) and an average service time (the average total time spent at the petrol station) $T$.

$$
N=\bar{\lambda} T
$$

$T$ was taken to be 5 minutes, which was verified by calculation: according to [21], the average throughput through a UK petrol station in 2017 was 6 million liters. For an average delivery of 40 liters, this implies 150,000 vehicles per petrol station per year. Over the year, this equates to 410 vehicles per day on average. Using a wait time of 5 minutes in (1) resulted in similar total arrivals. From the average arrival rate $\bar{\lambda}$ derived from (1), the number of arrivals for that hour $\lambda$ was sampled from a Poisson distribution with mean $\bar{\lambda}$ in accordance with the assumption of a Poisson arrival process for EV charging queue modelling used in [16]. The arrival rate profile for the same MC trial as in Fig. 3 is shown in Fig. 4.

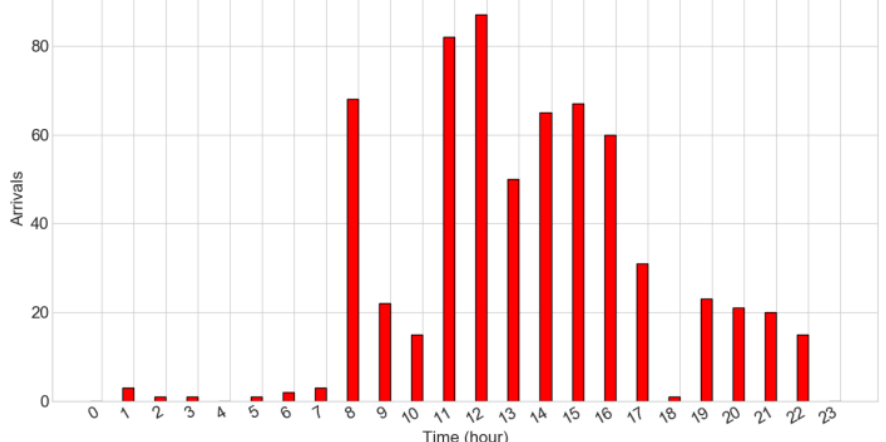

Figure 4. Arrivals per hour for one MC trial based on petrol station popularity data for Saturday
The arrival rate profile (Fig. 4) is input into the time sequential simulation in order to derive a demand profile characterisation of an $\mathrm{EV}$ fast charging forecourt.

\section{Time Sequential Simulation}

The time sequential simulation models the minute-to-minute activity of the forecourt, and hence its demand profile. For each hour, an array of 'car' objects equal to the number of arrivals in that hour (given by the height of the bars in Fig. 4) is instantiated and each car is assigned parameters which, along with the fixed forecourt parameters, will dictate the duration of each vehicle's charge and hence the time series of demand at the forecourt. The forecourt and vehicle parameters are illustrated in Fig. 5 and discussed in subsections 1 and 2 below.

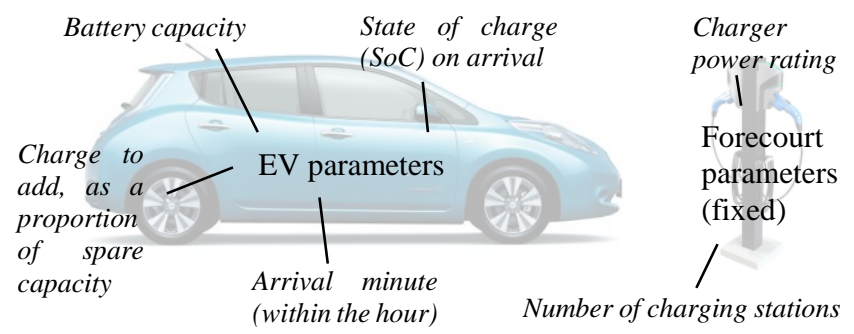

Figure 5. EV and forecourt parameters for time sequential simulation - images from [22] (left) and [23] (right)

\section{1) Forecourt Parameters}

\section{a) Number of charging stations}

The number of charging stations was selected as 8 , based on the number of stations considered in the forecourt in [15].

\section{b) Power rating of chargers}

The power rating of fast $\mathrm{EV}$ charging infrastructure is a trade-off between many factors: convenience to the user, limitation of battery stress and cost versus the local demand for using them. If charging rates are too low, users would face perhaps an unacceptable amount of inconvenience as they wait for their vehicles to charge. If they are too high, users may be deterred from using them at their rated capacity out of fear for reductions in battery life; capital costs for their acquisition and connection will also increase with charger rating. In the literature, charging rates for fast EV infrastructure are in the range 100-350 kW [15], [16], [24]. The rating for this work was chosen to reflect a reasonable queue size (explained in more detail in subsection 2), which was set such that the average maximum daily queue time of an 8-charging station forecourt over 10,000 trials would not exceed two minutes, in accordance with what would be considered normal at a current UK petrol station. For the 'all EVs' case (Fig. 6), this was set to $100 \mathrm{~kW}$ which gave an average maximum queue length of 2.0 minutes. For the 'BEVs only' case, this was set to $200 \mathrm{~kW}$ which gave an average maximum queue length of 1.9 minutes. Both were simulated for 10,000 trials for Saturday data. 


\section{2) Vehicle Parameters}

\section{a) Battery capacity}

A histogram showing the probability distribution of EV battery capacities (kWh) for UK sales in 2017 [3] is presented in Fig. 6, from which the simulated vehicle's battery size is randomly sampled. Two series are shown; one being for all EVs (including Battery Electric Vehicles (BEVs) and Plug-in Hybrid Electric Vehicles (PHEVs)) and one for BEVs only. It is perhaps reasonable to suppose that, as PHEVs have an internal combustion engine to rely on, BEV users (who normally have larger batteries to charge) would be more likely to charge at EV forecourts.

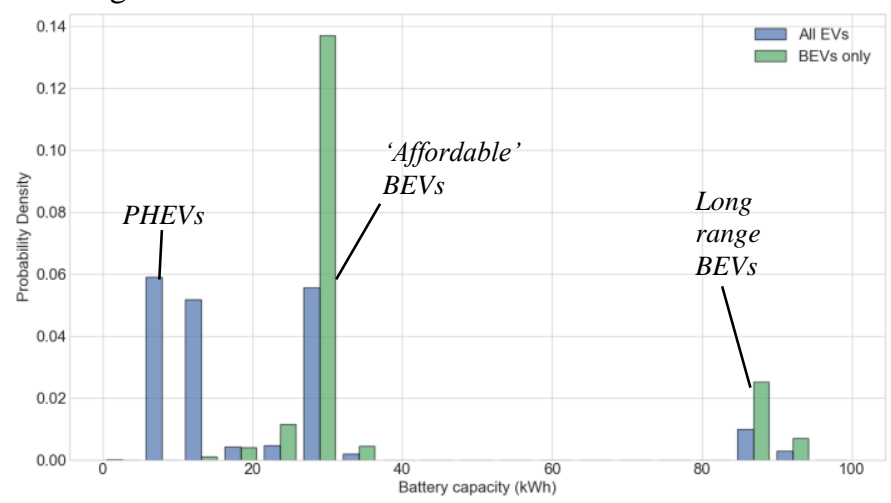

Figure 6. Histogram showing distribution of battery sizes for UK EV Sales, 2017 - data from [3]

If the 'BEVs only' option is selected then the energy requirement of vehicles increases due to their larger battery capacities. For a given charger capacity and number of charging stations, this has the effect of lengthening the queue as previously discussed. However, by increasing the charger power the queue can be kept to a similar length and the overall demand profile will tend towards a scaled version of that for the 'all EVs' case. Therefore, only results from the all EVs case are presented in this paper as an example of the method.

b) State of Charge (SoC) on arrival and added charge as a proportion of empty capacity

The SoC of a battery upon starting and finishing EV charging is often modelled by Gaussian distributions as exemplified by Qian et al [25]. However, Yi and Li [26] present $\chi^{2}$ test results to argue that a Beta distribution offers a better goodness of fit to real charging behaviour than a Gaussian distribution does. According to Marra et al. [27], a Li-ion EV battery should ideally be cycled between $20 \%$ and $90 \%$ SoC; this was used to inform the setting of Beta distribution parameters $\alpha$ and $\beta$. SoC on arrival is treated as an independent variable with $\alpha=2$ and $\beta$ $=5$, shown by the blue line in Fig. 7. This gives a modal SoC on arrival of $20 \%$ and a mean of $29 \%$. The post-charging SoC was derived by sampling a Beta distribution describing the added charge as a proportion of empty capacity, to ensure the EV cannot charge to above $100 \%$ or below its SoC on arrival.
Parameters for the added charge Beta distribution were tuned by taking one million samples from the $\mathrm{SoC}$ on arrival distribution (blue line) and the added charge distribution (green line) for various $\alpha$ and $\beta$ to produce a histogram of postcharging SoC. The probability of an EV leaving the forecourt with an SoC above $90 \%$ is less than $5 \%$, which reflects the ideal charging behaviour in [27] but allows some users to violate it. The added charge Beta parameters were set as $\alpha=3.2, \beta=2.6$.

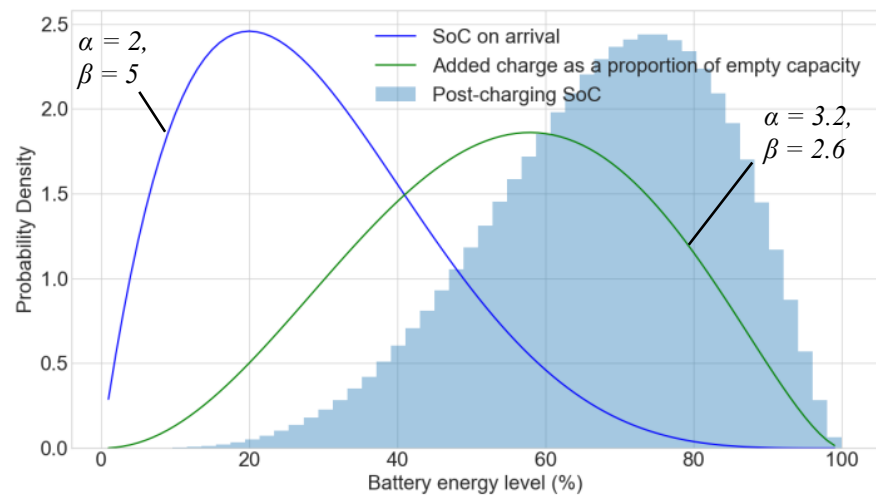

Figure 7. Beta distributions for SoC on arrival and added charge as a proportion of empty capacity

\section{c) Arrival time}

Within the hour, the vehicle's arrival minute is randomly assigned as a random integer between 0 and 59 .

\section{3) Queueing Model and Derivation of Demand Profile}

For each vehicle known to be using the forecourt on the simulated day, the charge duration can be calculated from (2), where $P_{\text {charger }}$ is the charger power $(\mathrm{kW})$ and $C_{\text {added }}$ is the added charge as a proportion of the battery's empty capacity. Note that although all EVs' arrival times are fixed within the hour by the arrival profile derived in Fig. 4, their leave time can be within the next hour if their charge duration lasts to the next hour.

$$
\text { Charge Duration }=(1-S o C) C_{\text {added }} P_{\text {charger }}
$$

The demand drawn by the forecourt at any given minute is equal to the number of cars connected multiplied by the charger power rating. To simulate busy periods at the forecourt, a queueing model is developed. Each time a car arrives it is assumed to begin charging immediately and leave when its charging time is finished, unless the number of vehicles connected is equal to the number of charging stations (i.e. the forecourt is full). In this case, the car must join a queue. The queue will continue to grow as more cars arrive and join the back of the queue. Cars will wait in the queue until the next vehicle leaves the forecourt, at which point the vehicle at the front of the queue connects to the free charger and their leave time is adjusted accordingly (their charge duration is assumed to be the same). It is assumed that vehicles join one queue for the forecourt and they take charging stations on a first come, first served basis. Once a vehicle joins the queue, it is committed to waiting to be charged and the queue length has no 
limit. At every minute, the number of cars connected multiplied by the charger power is equal to the electrical demand of the forecourt. Fig. 8 shows an example of the outputs for the same MC trial in Figs. 3 \& 4; the demand profile (left) and the number of vehicles queueing (right) for an 8 -station, $100 \mathrm{~kW}$ charger rating forecourt for the 'all EVs' case (see Fig. 6).
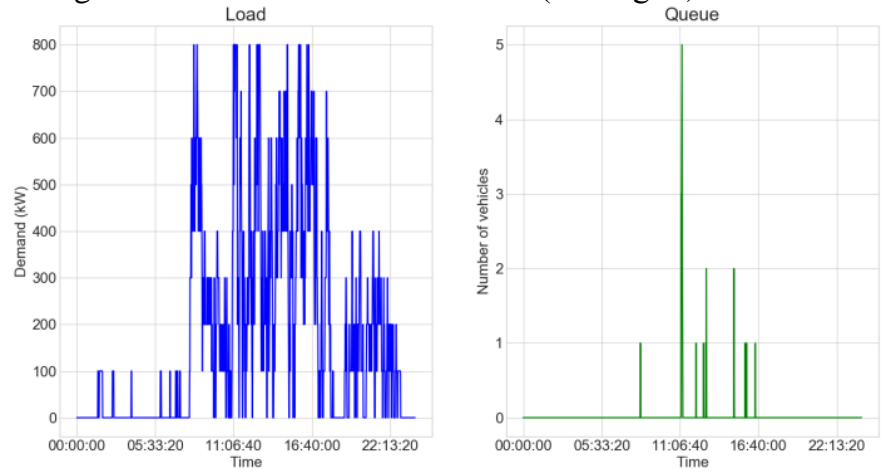

Figure 8. Expected load profile and queue length for one MC trial of an 8x100 $\mathrm{kW}$ EV charging forecourt, Saturday

\section{RESULTS}

\section{A. Monte Carlo Simulations of EV Forecourt Demand Profile}

Fig. 9 shows the average demand profile for an EV forecourt simulation of 10,000 trials based on the petrol station popularity data for Tuesday (blue) and Saturday (green) for an 8-station, $100 \mathrm{~kW}$ charger power forecourt for the 'all EVs' case.

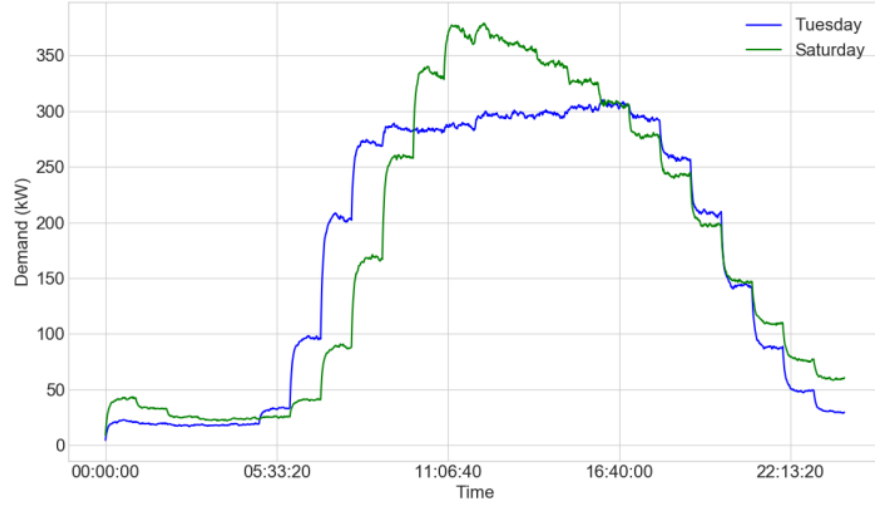

Figure 9. Expected demand profiles for Tuesday and Saturday based on simulation of an $8 \times 100 \mathrm{~kW}$ EV charging forecourt, 10,000 trials

Fig. 9 shows that on average, the daily demand peaks at around $40 \%$ of the rated maximum towards the mid-afternoon on a weekday and at around $45-50 \%$ of the rated maximum in the late morning on a weekend. The steps between hours are an artefact of the popularity data as shown in Fig. 1; in reality, the average demand profile would be smoother.

To investigate the probabilistic variation in demand, Fig. 10 shows the probability distribution of 10,000 trials of a simulation of the demand time series for a simulated EV forecourt on a Friday by a 3D histogram: for a given time of day, the probability that a simulated EV forecourt will draw a particular power demand is demonstrated by the bar height.

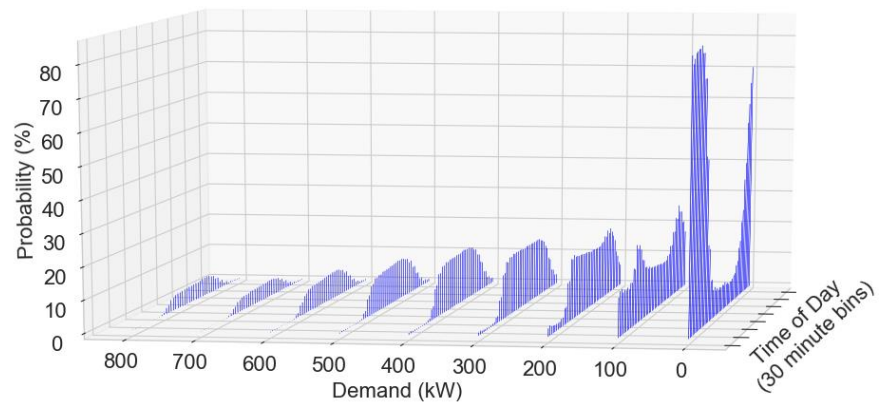

Figure 10. 3D histogram showing probability distribution of 10,000 trials of an $8 \times 100 \mathrm{~kW}$ forecourt simulation based on Friday popularity data

Fig. 10 shows that there is significant variation of the forecourt's demand levels for most of the day. The discrete nature of the distribution is due to the constant-charging assumption in the simulation; as the distribution reflects forecourt occupancy, the total demand of the forecourt can only take one of nine levels between 0 and $800 \mathrm{~kW}$. It is shown that probability reduces with increasing power, but there remains a fairly significant $(\sim 5-10 \%)$ likelihood of full output at peak time in the mid-afternoon.

\section{B. Statistical Comparison with Existing Network Load}

An EV charging forecourt at a rating of several hundred kilowatts would likely be connected at a primary distribution voltage level $(6-11 \mathrm{kV})$. Data from SP Energy Networks' Flexible Networks project (2013-2015) [28] were used to construct a probabilistic analysis of the combination of EV forecourt demand with that of existing $11 \mathrm{kV}$ feeders. Fig. 11 shows a CDF of the combined loading of 10,000 MC trials of an $8 \times 100 \mathrm{~kW}$ EV forecourt based on Tuesday popularity data with all monitored winter weekdays in the period 2013-2015 for St Andrews Feeder 24. St Andrews Feeder 24 has an existing winter weekday peak of $797 \mathrm{~kW}$ according to the data in [28]; therefore, the peaks of both loads are assumed equal. The combined load is expressed as a percentage of the original load.

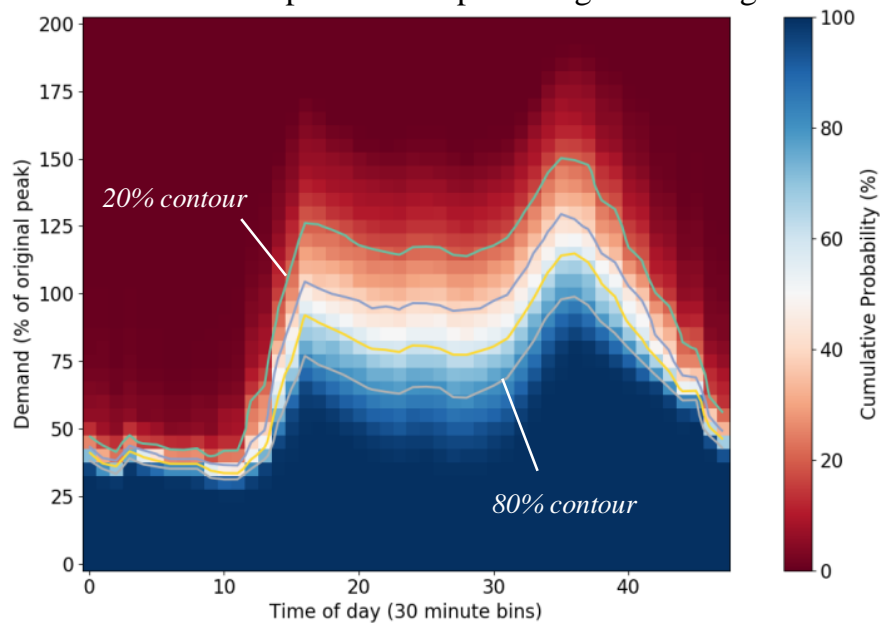

Figure 11. CDF of combined loading of $8 \times 100 \mathrm{~kW}$ EV forecourt simulation (Tuesday) and St Andrews Feeder 24, winter weekdays 2013-2015 
The method as demonstrated in Fig. 11 provides a quantification of the likelihood that the combined loading of the feeder after the integration of an EV forecourt will exceed a certain value. For example, there is a $20 \%$ probability based on the data in [28] and the simulation results presented in this paper that the feeder peak will exceed $150 \%$ of the original feeder peak at around 17:30 following the introduction of an EV forecourt of equal peak demand to the existing feeder demand.

\section{CONCLUSION AND FURTHER WORK}

This paper has presented a Monte Carlo-based method to characterise the electrical demand profile of EV fast charging forecourts, which are likely to be commonplace in high EVuptake scenarios. The characterisation is based on popularity data of current petrol stations from smartphone locational data collected by Google's Popular Times feature. It has been shown that there is likely to be significant variation in the demand of $\mathrm{EV}$ forecourts if it assumed that their usage patterns will be similar to that of current petrol stations. The statistical comparison method (Section III B) could be used across an entire distribution network to model uptake of various modes of EV charging and how the temporal variations in their demand interact with one another. This could then be used to assess the feasibility of 'smart' alternatives to traditional network reinforcement in preparing distribution networks for the widespread electrification of transport. Network operators could also build 'heat maps' showing the cost to connect EV fast charging load for different areas of network based on the scale of intervention required, therefore assisting the business case of EV fast charging and providing a better-utilized and lower-cost network for the energy consumer.

To improve the accuracy of the forecourt characterisations, further analysis of different types of petrol stations is recommended. It is discussed that the data collected was for different types of petrol stations (e.g. supermarkets, independently owned etc.); however, disaggregation would allow analysis on the basis of a number of more focused typespecific characteristions.

\section{REFERENCES}

[1] Department for Transport, "Vehicle Licensing Statistics: January to March 2017," 2017. [Online]. Available: https://goo.gl/xSRLhz. [Accessed: 20-Dec-2017].

[2] Department for Environment Food \& Rural Affairs, "UK plan for tackling roadside nitrogen dioxide concentrations," 2017. [Online]. Available: https://goo.gl/68h6ba.

[3] RAC Foundation, "Plug-in grant eligible vehicles licensed," 2017. [Online]. Available: https://goo.gl/ZnR1fZ. [Accessed: 20-Dec2017]

[4] Department for Transport, "Public experiences of and attitudes towards parking," 2008. [Online]. Available: https://goo.gl/PQo7qX. [Accessed: 20-Dec-2017].

[5] Innovate UK, "Plugin Vehicle 2025 Stakeholder Success Vision," 2017. [Online]. Available: https://goo.gl/T68cXD. [Accessed: 21Dec-2017].

[6] Energy Saving Trust/Department for Transport, "Learn how car clubs can improve your organisation's efficiency," 2013. [Online].
Available: https://goo.gl/LUYw6w.

[7] P. Kurzweil, "Chapter 16 - Lithium Battery Energy Storage: State of the Art Including Lithium-Air and Lithium-Sulfur Systems," in Electrochemical Energy Storage for Renewable Sources and Grid Balancing, Elsevier, 2015, pp. 269-307.

[8] Zap-Map, "Charging Point Statistics 2017," 2017. [Online]. Available: https://goo.gl/xZ45CH. [Accessed: 22-Nov-2017].

[9] National Grid, "Forecourt Thoughts: Mass fast charging of electric vehicles," 2017. [Online]. Available: https://goo.gl/8v2T2X. [Accessed: 20-Dec-2017].

[10] S. Mohtashami, D. Pudjianto, G. Strbac, and A. Constants, "Strategic Distribution Network Planning With Smart Grid Technologies," IEEE Trans. Smart Grid, vol. 8, no. 6, pp. 2656-2664, 2017.

[11] R. Moreno, D. Pudjianto, and G. Strbac, "Future transmission network operation and design standards to support a low carbon electricity system," IEEE PES Gen. Meet. PES 2010, 2010.

[12] S. Huang and D. Infield, "Monte Carlo modelling for domestic car use patterns in United Kingdom," 2014 Int. Conf. Connected Vehicles and Expo, pp. 68-73, 2015.

[13] A. Beltramo, A. Julea, N. Refa, Y. Drossinos, C. Thiel, and S. Quoilin, "Using electric vehicles as flexible resource in power systems: A case study in the Netherlands," 14th Int. Conf. European Energy Market, 2017.

[14] A. Lojowska, D. Kurowicka, G. Papaefthymiou, and L. Van Der Sluis, "Stochastic Modeling of Power Demand due to EVs Using Copula," IEEE Trans. Power Systems, vol. 27, no. 4, pp. 1960-1968, 2012.

[15] M. Etezadi-Amoli, K. Choma, and J. Stefani, "Rapid-charge electricvehicle stations," IEEE Trans. Power Delivery, vol. 25, no. 3, pp. 1883-1887, 2010.

[16] S. Bae and A. Kwasinski, "Spatial and Temporal Model of Electric Vehicle Charging Demand," IEEE Trans. Smart Grid, vol. 3, no. 1, pp. 394-403, 2012.

[17] "Popular Times - Google Maps Entry for Tesco Petrol Station, Glasgow G21 1YL." [Online]. Available: https://goo.gl/Ym4ZGZ. [Accessed: 24-Jan-2018].

[18] RAC Foundation/Deloitte, "UK Fuel Market Review," 2013. [Online]. Available: https://goo.gl/twk6ge.

[19] Deloitte, "Mobile Consumer Survey," 2016. [Online]. Available: https://goo.gl/CHJNFr.

[20] ComScore, "The 2017 U.S. Mobile App Report." [Online]. Available: https://goo.gl/Bfw3UW.

[21] UK Petroleum Industry Association, "Statistical Review 2017," 2017. [Online]. Available: https://goo.gl/x6BjfR.

[22] Nissan, "Leaf," 2017. [Online]. Available: https://goo.gl/W1byqZ. [Accessed: 21-Dec-2017].

[23] National Car Charging, "AeroVironment TurboDock Dual Pedestal Mount EV Charging Station." [Online]. Available: https://goo.gl/nkQc6D. [Accessed: 30-Jan-2018].

[24] Z. Zhou and T. Lin, "Spatial and temporal model for electric vehicle rapid charging demand," 2012 IEEE Vehicle Power Propulsion Conf., pp. 345-348, 2012.

[25] K. Qian, C. Zhou, M. Allan, and Y. Yuan, "Modeling of load demand due to EV battery charging in distribution systems," IEEE Trans. Power Systems, vol. 26, no. 2, pp. 802-810, 2011.

[26] F. Yi and F. Li, "An exploration of a probabilistic model for electric vehicles residential demand profile modeling," IEEE Power Energy Society General Meeting, 2012.

[27] F. Marra, G. Y. Yang, C. Traholt, E. Larsen, C. N. Rasmussen, and S. You, "Demand profile study of battery electric vehicle under different charging options," IEEE Power Energy Society General Meeting, 2012.

[28] SP Energy Networks, "Flexible Networks for a Low Carbon Future." [Online]. Available: https://goo.gl/PyGyH7. [Accessed: 28-Sep2017]. 